\title{
A Study on the Relationship Between College Students' Psychological Capital and Their Employability
}

\author{
Jin $\mathrm{Ma}^{1, *}$ \\ ${ }^{1}$ School of Economics and Management, Beijing Jiaotong University, China, 100044 \\ ${ }^{*}$ Corresponding author. Email: 19120705@bjtu.edu.cn
}

\begin{abstract}
In recent years, college education has gradually changed from elite education to universal education. Meanwhile, the employment difficulty of college graduates has become a common problem. From the perspective of psychological capital, this study investigates the impact of psychological capital (including self-efficacy, hope, optimism and resilience) on college students' employ-ability through a questionnaire survey of 107 undergraduates from an university in Beijing. On the basis of summarizing previous research results and establishing logistic regression model and multiple linear regression model, it is concluded that cultivating college students' level of self-efficacy, hope and optimism will play an important role in improving their employability. Finally, some suggestions are put forward from the view of universities.
\end{abstract}

Keywords: Psychological capital, Employ-ability, Self-efficacy.

\section{INTRODUCTION}

The employment situation of college students has always been the concern of the whole society. In recent years, the phenomenon of college students being unemployed after graduation has become more prominent. It can be seen that college degrees are not as rare as many years ago, and the employment situation of college students is not like the "equal distribution", which leads to a severe situation of college students' employment and fierce competition. Human capital, social capital and economic capital all play a certain role in the employment of college students. However, another important factor, psychological capital, has not received enough attention. Psychological capital plays an important role in students' application of their own quality, exploration of their own potential and expansion of social relations.

By taking a municipal university in Beijing as an example, this study explores the relationship between psychological capital and employability of college students. Through the study of the psychological capital of college students, the employment ability of college students to develop, to find a better idea of employment; From the perspective of colleges and universities, it is necessary to explore how to educate college students.

\section{LITERATURE REVIEW}

\subsection{Psychological Capital}

Psychological capital refers to a positive mental state manifested by individuals in the process of growth and development. Luthans et al. (2005) for the first time explicitly defined psychological capital as the core psychological elements of individual initiative, specifically manifested as a psychological state conforming to the standard of positive organizational behavior, which transcends human capital and social capital.[1] Luthans and Avolio (2007) revised the definition of psychological capital. They pointed out that psychological capital is the positive psychological development state of individuals. Luthans believes that self-efficacy, resilience, hope and optimism are the four forms of positive state of psychological capital. Based on the above analysis, psychological capital refers to the positive psychological resources possessed by individuals. It is the positive psychological power of an individual whose components are self-efficacy, resilience, hope and optimism. Psychological capital, human capital and social capital constitute the human resources of an individual. In addition, human capital is easy to detect, measure and master. But it is difficult to observe, measure and develop psychological capital. 


\subsection{Employability}

There is no uniform definition of employability due to different disciplinary backgrounds. Hillage and Pollard(1998) argue that employability is the ability to obtain initial employment, maintain employment and, if necessary, acquire new employment;[2] Fuguate(2001) believes that employability refers to the individual's ability to identify and realize career opportunities within and outside the organization during their career, which is a kind of psychological and social construction embedded in personal characteristics.[3] Both definitions define employability in terms of the purpose of seeking employment. This study also understands from this perspective, that the employability of college students is the ability, character, intention and other comprehensive characteristics that they should have in their career to obtain personal satisfaction. Yorke and Knight believe that employability refers to the ability of college students to obtain and continuously improve their ability and personal characteristics, so that they can more easily obtain employment, and then obtain professional success. [4]

\section{THE RESEARCH MODEL AND HYPOTHESIS}

\subsection{Psychological Capital and Employability}

Scholars generally believe that psychological capital has a significant positive impact on employability. For example, Wang Yaojun (2013) conducted a questionnaire survey among 251 college students. The influence of psychological capital on the employability of college students is discussed. [5] The research shows that the three dimensions of self efficiency, resilience and optimism in psychological capital have a positive impact on employability. Shen Xiaomei (2013) conducted a questionnaire survey among 573 college students, and analyzed the correlation between psychological capital and employability of College Students.[6] The results show that psychological capital of college students has a significant impact on their employability. Based on the above analysis, the following research hypotheses are put forward:

H1: College students' psychological capital has a significant positive impact on their employability.

H1a: Self-efficacy has a significant positive impact on College Students' employability.

H1b: Resilience has a significant positive impact on College Students' employability.

H1c: Hopes to have a significant positive impact on College Students' employability.

H1d: Optimism has a significant positive impact on College Students' employability.

\subsection{The Moderating Effect of Gender}

So far, the impact of gender on the relationship between psychological capital and employability has not been widely studied. $\mathrm{Hu}$ Yanhua, Cao Xuemei and Jing Ying (2018) measure 450 college students through psychological capital scale, career exploration scale and college employability scale, and analyze career exploration as a mediator variable. The relationship between psychological capital and employability of college students shows that gender affects college students' psychological capital, career exploration and employability. Boys' career decision- making and employability scores are significantly higher than those of girls.[7] Based on the above analysis, the following research hypotheses are put forward:

H2: Gender regulation of College Students' psychological capital has an impact on their employability.

H2a: Gender moderates the influence of College Students' self-efficacy on their employability.

$\mathrm{H} 2 \mathrm{~b}$ : Gender moderates the resilience of college students to their employability.

H2c: Gender moderates the influence of College Students' hope level on their employability.

$\mathrm{H} 2 \mathrm{~d}$ : Gender moderates the influence of College Students' optimism on their employability.

Based on the above theoretical analysis, the research model framework is shown in Figure 1.

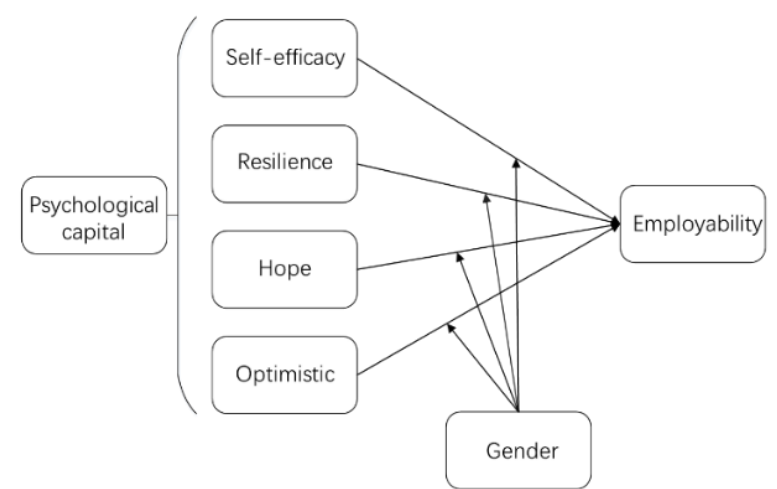

Figure1 Confirmatory factor analysis model

\section{RESEARCH METHODOLOGY AND ANALYSIS}

\subsection{Measurement and Data Collection}

This research mainly adopts the questionnaire survey method. The measuring tools are all developed by the existing research scale. The questionnaire adopts the self-evaluation method, and the subjects are asked to answer according to their true feelings.

The psychological capital questionnaire was compiled by Zhang Kuo, Zhang Sai and Dong Yinghong 
in 2010, which mainly consisted of four dimensions, including self-efficacy, resilience, hope and optimism. There were 26 items in total. The questionnaire used seven levels of Likert scale.

The employability questionnaire was compiled by Yu Haibo in 2013, which consisted of five dimensions, including social support, team work, interpersonal relationship, learning ability and network difference. There were 19 items in the questionnaire. The questionnaire consisted of five levels of Likert scale.

\subsection{Sample Selection and Data Collection}

In order to control the impact of students' personal characteristics on research, this paper takes gender and profession as control variables. This research mainly adopts the questionnaire survey method. The data were collected from August 2020 to September on the Internet, and the subjects were students from universities in Beijing. 120 questionnaires were distributed in this survey. After screening the invalid questionnaire with short answer time and consistent answers, the total number of valid questionnaires was 107, the effective rate of the questionnaire was $89.2 \%$.

According to the 107 questionnaires, there were 46 male students, accounting for $42.99 \%$, and 61 female students, accounting for 57.01\%.Among them, economics majors account for $14.95 \%$, literature $9.35 \%$, Science majors $11.21 \%$, philosophy $4.67 \%$, engineering majors $19.63 \%$, law majors $6.54 \%$, management majors $27.1 \%$, art majors $4.67 \%$ and other majors $1.87 \%$.

\subsection{Reliability and Validity Test}

Before the hypothesis testing, the reliability and validity of the sample data were analyzed. As can be seen from Table 1, the overall reliability coefficient of the psychological capital scale is 0.933 , with good reliability, so the scale has certain reliability. The overall reliability coefficient of the employability scale is 0.908 , and the reliability coefficient of each dimension is above 0.7 , showing good internal consistency.

Table 1. Scaling of reliability test

\begin{tabular}{|c|c|c|c|c|}
\hline Constructs & Measurement items & Number & Cronbach's $\alpha$ & Total Cronbach's $\alpha$ \\
\hline \multirow{4}{*}{ Psychological capital } & Self-efficacy & 7 & 0.801 & \multirow{4}{*}{0.933} \\
\hline & Resilience & 7 & 0.765 & \\
\hline & Hope & 6 & 0.751 & \\
\hline & Optimistic & 6 & 0.859 & \\
\hline \multirow{5}{*}{ Employability } & Social Support & 4 & 0.847 & \multirow{5}{*}{0.908} \\
\hline & Teamwork & 3 & 0.796 & \\
\hline & Interpersonal Relationship & 5 & 0.854 & \\
\hline & Learning ability & 4 & 0.795 & \\
\hline & Network difference & 3 & 0.787 & \\
\hline
\end{tabular}

Table 2. Correlation coefficient matrix

\begin{tabular}{|c|c|c|c|c|c|c|c|c|c|}
\hline & Mean & SD & 1 & 2 & 3 & 4 & 5 & 6 & 7 \\
\hline 1-Gender & - & - & 1 & & & & & & \\
\hline 2-Major & - & - & -0.078 & 1 & & & & & \\
\hline 3- Self-efficacy & 4.760 & 0.771 & -0.026 & $0.232 *$ & 1 & & & & \\
\hline 4- Resilience & 4.250 & 0.672 & $0.223^{*}$ & 0.046 & $0.517 * *$ & 1 & & & \\
\hline 5-Hope & 4.854 & 0.723 & -0.028 & 0.165 & $0.622^{* * *}$ & $0.342 * *$ & 1 & & \\
\hline 6- Optimistic & 5.171 & 1.014 & 0.035 & 0.134 & $0.743 * *$ & $0.482 * *$ & $0.659 * *$ & 1 & \\
\hline 7- Employability & 4.759 & 0.659 & -0.153 & 0.148 & $0.699 * *$ & $0.272 * *$ & $0.678 * *$ & $0.739 * *$ & 1 \\
\hline
\end{tabular}


Confirmatory factor analysis was performed on 107 valid questionnaires using AMOS 20 statistical analysis software. Among the fitting indexes of the four-dimensional model of psychological capital, the chi-square degree of freedom ratio is $2.946<3$. RMSEA is 0.1. According to Steiger (1990), RMSEA indicator between 0.05 and 0.1 indicates a good fit. Among the fitting indexes in the five dimensions of employability, the chi-square degree of freedom ratio is $1.826<2$. RMSEA is 0.08 , and the fitting result was good.

As shown in Table 2, the four dimensions of psychological capital are significantly correlated with employability, and all of them are positively correlated. Among them, the correlation coefficient between self-efficacy and employability is 0.699 , the correlation coefficient between resilience and employability is 0.272 , the correlation coefficient between hope and employability is 0.678 , and the correlation coefficient between optimism and employability is 0.739 .

\subsection{Reliability and Validity Test}

Multiple regression analysis was carried out on the four factors of psychological capital (self-efficacy, hope, optimism, resilience) and employability. All the four factors had a significant impact on employability, but the regression coefficient of resilience dimension was -0.142 , which had a negative impact on employability, contrary to the hypothesis. Considering that it may be caused by collinearity, ridge regression was used for analysis.

Table 3. Regression analysis results

\begin{tabular}{|c|c|}
\hline Variable & Employability \\
\hline Constant & $3.987 * * *$ \\
\hline Gender & $-0.097 *$ \\
\hline Major & 0.004 \\
\hline Self-efficacy & $0.128 * * *$ \\
\hline Resilience & 0.002 \\
\hline Hope & $0.128 * * *$ \\
\hline Optimistic & $0.148 * * *$ \\
\hline $\mathrm{R}^{2}$ & 0.596 \\
\hline Adjust $\mathrm{R}^{2}$ & 0.572 \\
\hline $\mathrm{F}$ & $24.622 * * *$ \\
\hline
\end{tabular}

From Table 3, we can see that gender, major, self-efficacy; resilience, hope and optimism are independent variables. Ridge regression (ridge regression) analysis is used as the dependent variable of employability. The $\mathrm{K}$ value is 0.990 .

From the above table, we can see that the $\mathrm{R}^{2}$ value of the model is 0.596, which means gender, major, self-efficacy, resilience, hope and optimism can explain the $59.6 \%$ causes of change in employability. The regression coefficient of self-efficacy is $0.128(\mathrm{t}=7.425$, $\mathrm{P}=0.000<0.01)$, which means that self-efficacy has a significant positive impact on employability. The regression coefficient of resilience is $0.002(\mathrm{t}=0.095$, $\mathrm{P}=0.924>0.05)$, which means that resilience does not affect employability. The expected regression coefficient is $0.128 \quad(\mathrm{t}=6.879) . \mathrm{P}=0.000<0.01)$, which means that the hope has a significant positive impact on employability. The optimistic regression coefficient is $0.148(\mathrm{t}=8.528, \mathrm{P}=0.000<0.01)$, which means that optimism has a significant positive impact on employability. Optimism has a significant positive impact on employability. Resilience does not affect employability. Therefore, assuming that $\mathrm{H} 1 \mathrm{a}, \mathrm{H} 1 \mathrm{c}$ and H1d are established, H1b is not valid.

In order to test the moderating effect of gender on psychological capital and employability, introducing the interaction items of psychological capital factors and gender on the basis of model 1, and regression analysis is carried out. Regression results show that the model 2 is relative to model $1 . \mathrm{R} 2$ increased by 0.033 , hoping that the regression coefficient of gender interaction items is more significant, indicating that gender plays a moderating role in the relationship between hope and employability, and the moderating effect is shown in Figure 2.

By drawing the diagram, this study found that the positive impact of hope level on male college students' employability is stronger than that of female college students. Therefore, suppose $\mathrm{H} 2 \mathrm{c}$ is established, while the regression coefficients of three interaction items of gender and self-efficacy, resilience and optimism are not significant. It shows that gender does not have a moderating effect on the relationship between self-efficacy, resilience, optimism and employability. Therefore, the hypothesis $\mathrm{H} 2 \mathrm{a}, \mathrm{H} 2 \mathrm{~b}$ and $\mathrm{H} 2 \mathrm{~d}$ have not been verified. In conclusion, self efficacy, hope and optimism have significant positive effects on College Students' employability. Gender regulates the influence of College Students' hope level on their employability. The revised model is shown in Figure 3.

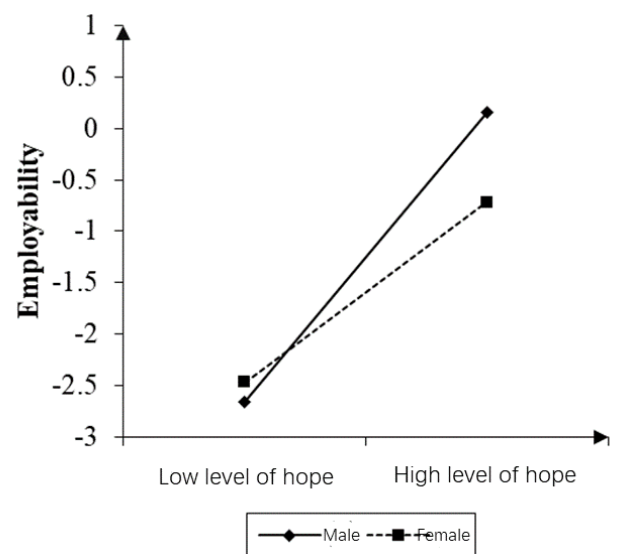

Figure 2 The moderating effect of gender. 


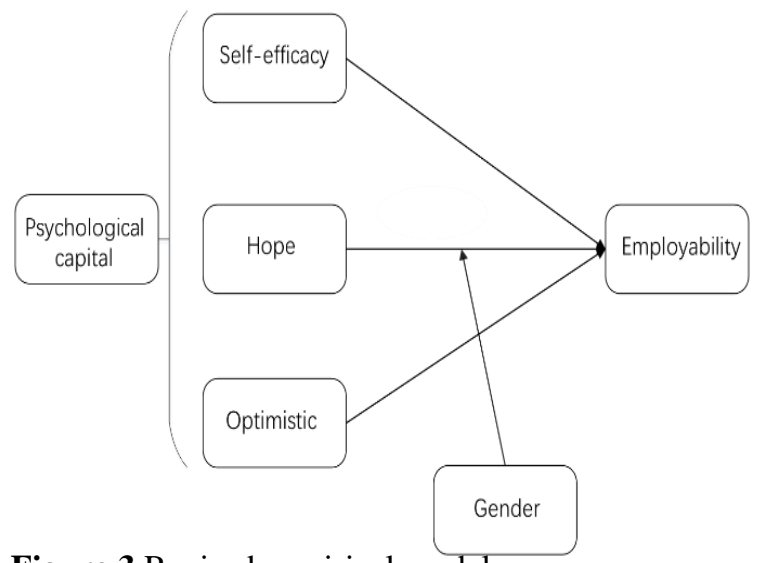

Figure 3 Revised empirical model

\section{CONCLUSION AND DISCUSSION}

The three factors of psychological capital, self-efficacy, hope and optimism, have a significant positive effect on the employability of the university students. Thus it can be seen that the richer the psychological capital accumulation is, the stronger the employability will be. Cultivating students' sense of self-efficacy, level of hope and degree of optimism plays an important role in improving their employability. Moreover, gender has a significant moderating effect on the role between the dimension of hope and employability. When gender is the moderating variable, the effect of male college students' hope level on their employability is significantly greater than that of female college students. From the results of the study, we can see that psychological capital plays a positive and important role in improving the employability of college students. While implementing the traditional university education, we should attach importance to the effective development of College Students' psychological capital and improve their employability comprehensively and effectively. Higher education should better reflect the value of higher education. Universities should attach importance to the development of students' psychological capital in education, teaching and practice.

\section{REFERENCES}

[1] Psychological capital [M]. Luthans, America, 2007

[2] Hillage J , Pollard E. Employability: developing a framework for policy analysis[J]. 1999.

[3] Fugate M, Kinicki A J, Ashforth B E . Employability: A psycho-social construct, its dimensions, and applications [J]. Journal of vocational behavior, 2004, 65(1):p.14-38.

[4] Yorke M, Knight P T. Embedding employability into the curriculum [R]. York: The Higher Education Academy, 2006.

[5] Wang Yaojun. Influence of psychological capital on College Students' employability [J]. applied psychology, 2013,19 (01): 65-71+79.

[6] Shen Xiaomei. Cultivation of College Students' employability based on psychological capital [J]. Chinese higher education research, 2013 (12): 90-93.

[7] Hu Yanhua, Cao Xuemei, Jing Ying. The relationship between psychological capital and employability of College Students -- the mediating role of areer exploration $[\mathrm{J}]$. Journal of Shijiazhuang University, 2018, 20 (06): 141-146. 